\title{
Successful Endoscopic Treatment of a Patient with Delayed Diagnosed Boerhaave's Syndrome Using Two Ovesco-Clips and SEMS
}

\author{
Petko Karagyozov', Ivan Tishkov' ${ }^{1}$, Tcvetan Minchev ${ }^{2}$ and Kiril Draganov ${ }^{3 *}$ \\ ${ }^{1}$ Interventional Gastroenterology Department, Acibadem City Clinic Tokuda Hospital, Bulgaria \\ ${ }^{2}$ Department of Thoracic Surgery, Acibadem City Clinic Tokuda Hospital, Bulgaria \\ ${ }^{3}$ Clinic of Liver, Biliary, Pancreatic and General Surgery, Acibadem City Clinic Tokuda Hospital, Bulgaria
}

*Corresponding author: Kiril Draganov, Clinic of Liver, Biliary, Pancreatic and General Surgery, Acibadem City Clinic Tokuda

Hospital, Sofia, Bulgaria

\begin{abstract}
ARTICLE INFO
Received: 幽 November 12, 2020

Published: 㓞 November 23, 2020

Citation: Petko Karagyozov, Ivan Tishkov, Tcvetan Minchev, Kiril Draganov. Success-

ABSTRACT

Esophageal perforation (EP) remains a life-threatening condition despite the progress in modern medicine. Morbidity and mortality rates are still high especially in delayed diagnosed cases. Interventional gastroenterology is an alternative to high-risk surgical procedures and offers satisfactory results especially in elder and comorbid patients. We report such a case of a late clinical presentation of complicated spontaneous EP treated by a combination of two OTSCs and a SEMS in order to close the defect.
\end{abstract} ful Endoscopic Treatment of a Patient with Delayed Diagnosed Boerhaave's Syndrome Using Two Ovesco-Clips and SEMS. Biomed J Sci \& Tech Res 32(1)-2020. BJSTR. MS.ID.005194.
Keywords: Esophageal Perforation; Boerhaave's Syndrome; Interventional Endoscopy

\section{Introduction}

Esophageal perforation (EP) remains a life-threatening condition despite the advancements of surgery, interventional gastroenterology and intensive care medicine. The most common causal factor is Iatrogenic - upper GI endoscopy, nasogastric tube insertion, surgery, endotracheal intubation, etc. [1]. A transmural EP may also occur after excessive vomiting. Such a "spontaneous" perforation is known as Boerhaave's syndrome as first described by Dr. Herman Boerhaave in 1724 [2]. EP is associated with high mortality rate reaching $10 \%$ for all cases and even $50 \%$ when the diagnostics have been delayed [3]. The treatment scheme consists of patient resuscitation and broad-spectrum antibiotics followed by surgical repair [4]. Surgery on its turn is associated with high morbidity and mortality as well as prolonged hospital stay. Recent progress in interventional endoscopy introduced minimally invasive approaches - over-the-scope clips, stenting, endoscopic suturing devices, etc. [4-9].

\section{Case Presentation}

A 71 -year old man was admitted to the surgical department of another hospital with deteriorating clinical condition, chest pain and fever. The patient reported severe vomiting 2 weeks before admission, but there was no subcutaneous emphysema as one of the features in the classic Mackler's triad. Thoracic X-ray discovered massive right pleural effusion and CT-scan confirmed right pleural empyema. Thoracotomy achieved empyema evacuation and pleural space debriding, but the patient condition did not improve. Gastric content was secreted from the pleural drainages on 3. Day after surgery. A follow-up CT-scan suspected EP since it discovered a contrast leakage. The patient was referred to our institution for further treatment. An upper endoscopy documented a complete wall laceration measured 25/10 mm with tight edges and granulations at the esophagogastric junction (Figure 1). The CT scan found a distal EP as the contrasting substance leaked in the right pleural 
cavity. OTSC /Ovesco, Tubingen, Germany/ placement was the first method of choice attempting to close the defect. The perforation was too large and a single OTSC did not achieve a satisfactory result.

This necessitated an additional second clip that managed a successful complete defect closure (Figure 2). A gastrografin study right after the procedure revealed no leakage. However, a control CTscan on 8. Day after the procedure (oral contrast in-take) showed a low debit persisting leakage at the level of the clips into the pleural cavity (Figure 3). Second endoscopy was performed confirming a small defect between the two OTSCs. (Figure 4). A covered self- expandible metal stent /Wallstent; Boston Scientific, Marlborough, Massachusetts, USA/ was placed at the clips level (Figure 5). A follow-up gastrografin study showed no contrast leakage. The patient condition rapidly improved. Follow up CT scan on 13. Day showed almost complete resolution of the pleural effusion. The patient started oral in-take on 14. Day and was discharged on 18. Day. Due to severe comorbidities /COPD, HCV liver cirrhosis/ we decided not to remove the esophageal SEMS. Follow up chest X-ray and esophagogram 2 months later did not show any pathologic findings.

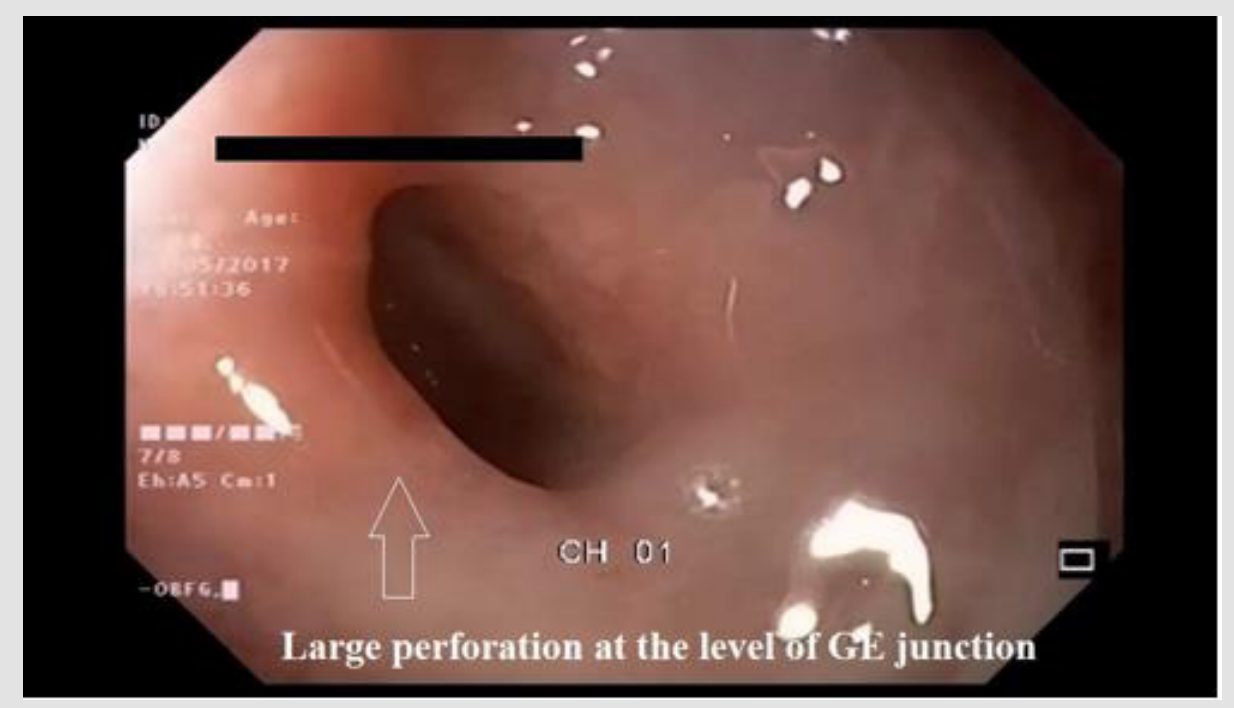

Figure 1: Endoscopic view of large perforation at the level of esophagogastric junction.

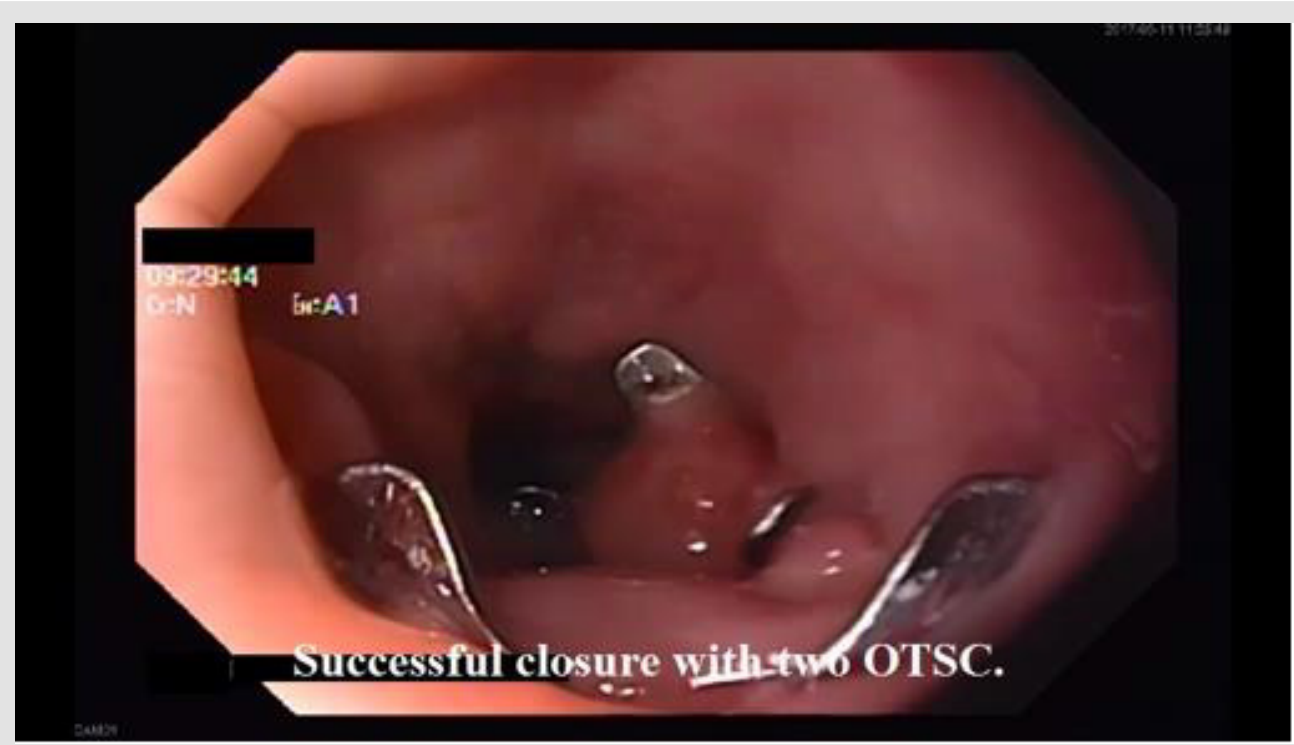

Figure 2: Successful closure using 2 OTSCs. 


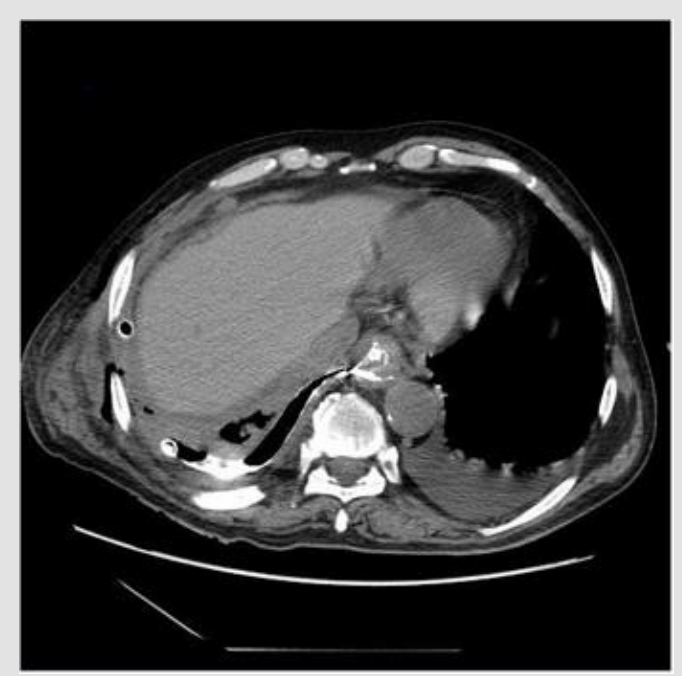

Figure 3: CT- scan with peroral contrast showing small leak at the level of the clips into the right pleural cavity.

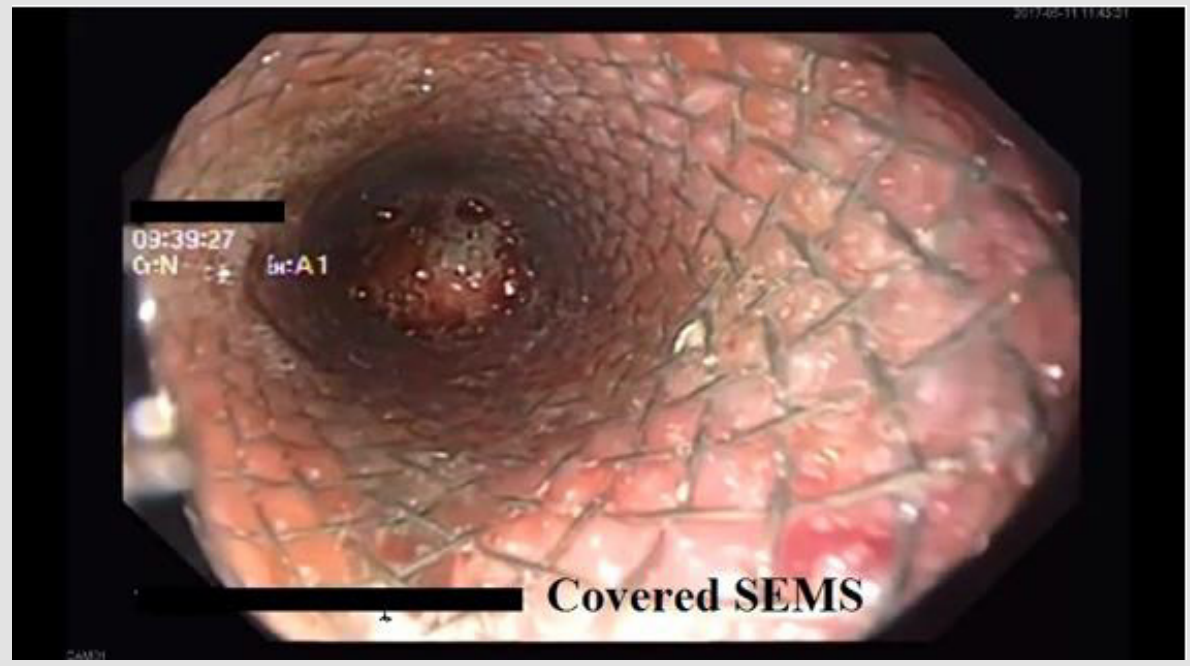

Figure 4: Covered SEMS at the level of the clips.

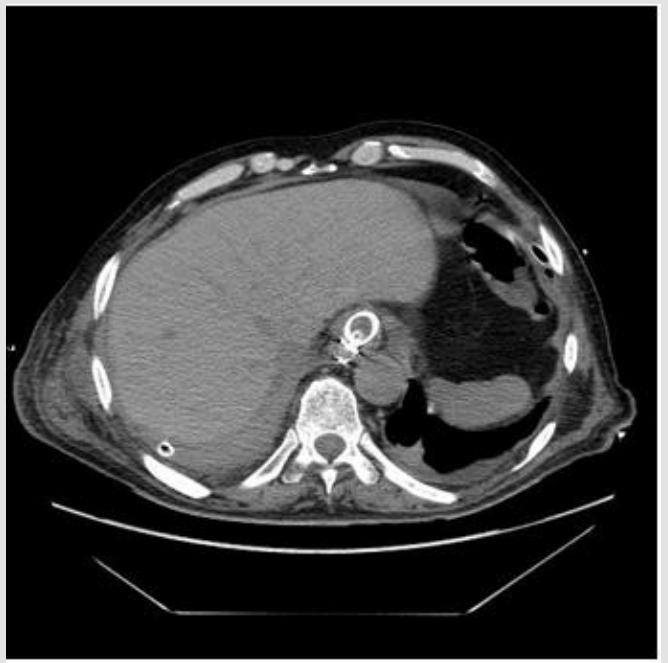

Figure 5: Follow up CT-scan on the $13^{\text {th }}$ day showing almost complete resolution of the pleural effusion. 


\section{Discussion}

EP is a dramatic emergency with poor prognosis, especially in cases of delayed diagnosis. Surgery in these cases is related with high morbidity and mortality especially in elderly and multimorbid patients. Endoscopic treatment is a suitable option for early recognized perforations [6-9]. The case is unusual because of the late presentation of complicated spontaneous perforation of the esophagogastric junction of an elderly multimorbid patient. We used a combination of two OTSCs and a SEMS in order to close the defect. A single clip was not sufficient to close the ruptured area, so we used a second one achieving complete closure. Due to the severe inflammation and the rigidity of tissues there was a minor persistent defect between the two clips, successfully managed with the SEMS. We also believe that we reduced the risk of SEMS migration causing stenosis by the two OTSC.

\section{References}

1. Maurya VK, Sharma P, Ravikumar R, Bhatia M (2016) Boerhaave's syndrome. Med J Armed Forces India 72(Suppl 1): S105-S107.

2. Adams BD, Sebastian BM, Carter J (2006) Honoring the Admiral: Boerhaave-van Wassenaer's syndrome. Dis Esophagus 19(3): 146-151.
3. Klin B, Berlatzky Y, Uretzky G (1989) Boerhaave's syndrome: case report and review of the literature. Isr J Med Sci 25(2): 113-115.

4. White RK, Morris DM (1992) Diagnosis and management of esophageal perforations. Am Surg 58(2): 112-119.

5. Costamagna G, Marchese M (2010) Management of esophageal perforation after therapeutic endoscopy. Gastroenterol Hepatol (NY) 6(6): 391-392.

6. Li Y, Wu J, Meng Y, Zhang Q Gong W, et al. (2016) New devices and techniques for endoscopic closure of gas- trointestinal perforations. World J Gastroenterol 22(33): 7453-7462.

7. Paspatis G, Dumonceau JM, Barthet M, Meisner S, Repici A, et al. (2014) Diagnosis and management of iatrogenic endoscopic perforations: European Society of Gastrointestinal Endoscopy (ESGE) Position Statement. Endoscopy 46(8): 693-711.

8. Van Boeckel PGA, Dua KS, Weusten BALM, Schmits RJH, Surapaneni N, et al. (2012) Fully covered self-expandable metal stents (SEMS), partially covered SEMS and self-expandable plastic stents for the treatment of benign esophageal ruptures and anastomotic leaks. BMC Gastroenterol 12: 19.

9. Ono H, Tanaka M, Takizawa K, Kakushima N, Kawata N, et al. (2015) Utility of the over-the-scope-clip system for treating a large esophageal perforation. Esophagus 12(3): 336-339.
ISSN: 2574-1241

DOI: 10.26717/BJSTR.2020.32.005194

Kiril Draganov. Biomed J Sci \& Tech Res

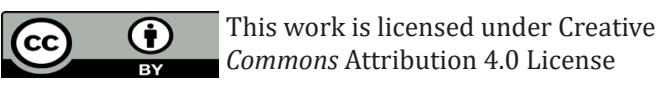

Submission Link: https://biomedres.us/submit-manuscript.php

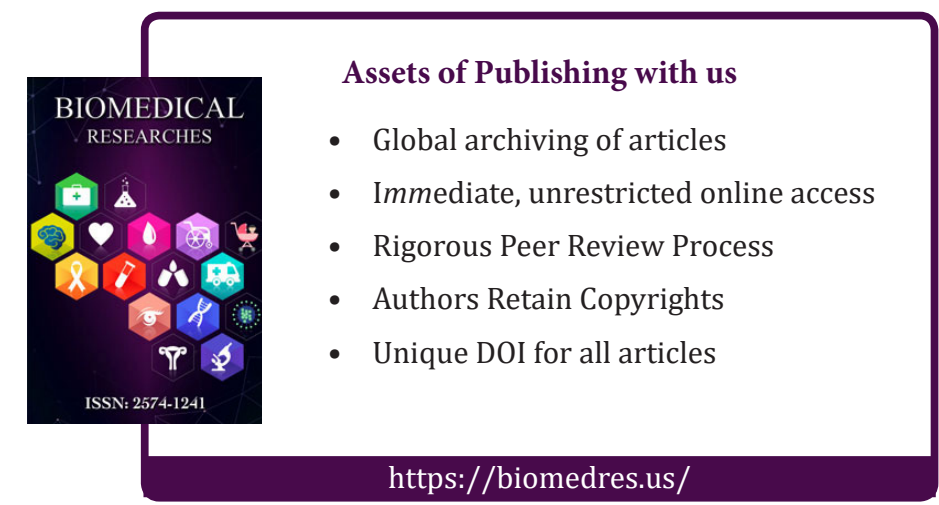

